\title{
Service Quality in One Window Service Office (OWSO): Reflection from Takhmao Municipality, Cambodia
}

\author{
Vutha Seng \\ Graduate School of Public Administration (GSPA), Burapha University, Thailand \\ Email: svutha@yahoomail.com
}

\begin{abstract}
This paper examined the level of service quality of One Window Service Office (OWSO) as perceived by clients at the Takhmao municipality, Cambodia. It also explored the challenges of the OWSO to propose possible guideline for improving service delivery. The SERVQUAL components were used to measure clients' expectations and perceptions. The quantitative data were collected from two different groups of clients $(n=170)$ while the qualitative data were collected from both clients $(n=10)$ and OWSO officers $(n=5)$ through in-depth interview.

The findings from survey questionnaires revealed that clients were satisfied with the Takhmao OWSO for delivering services. This was evident from the positive gap score $(\bar{X}=.47, S D=.68)$. However, according to the results obtained from the interviews, it emerged that there were some shortfalls still existing in OWSO. In this respect, the study has suggested a number of modifications to the OWSO management team to take into account for the sake of service delivery betterment.
\end{abstract}

Keywords: One Window Service Office (OWSO), Service Quality, Clients' Expectations, Clients' Perception, SEVQUAL

\section{Phenomena}

In the current regional change such as the ASEAN Economic Community (AEC) which will be launched in 2015, reformations in service delivery are very important for the Kingdom of Cambodia to adapt itself to this contestability situation. Over recent decades, the Royal Government of Cambodia (RGC) has tried to determine how to improve the service quality in the public sector. Administrative, legal and judicial systems have been carefully reformed to strengthen a rule of law, good governance and importantly to meet the requirements of the AEC charter. As noticed, two democratic systems of government namely Decentralization, and Deconcentration (D\&D) were introduced in Cambodia in 2001 and 2005 respectively. To pursue its visions for cultivating the structures and administrations of the local governments and achieving of good public service delivery, the RGC established a new mechanism for providing public service delivery. It is called One Window Service Office (OWSO) which was implemented in 2008. This research paper intended to examine the level of service quality as perceived by clients and explored the challenges of OWSO in providing public services.

\section{Literature Review}

\subsection{Service Quality}

Parasuraman, Zeithml and Berry (1985) defined service quality as the capability of the organization to reach clients' expectations. It is determined by the differences between clients' expectations of service provider's performance and their evaluation of the service they received. Brysland and Curry (2001) specified that service quality is about providing something intangible in a way that is both please and give values to the clients. If expectations are greater than performance, then perceived quality is less than satisfactory and hence client's dissatisfaction occurs (Parasuraman et al., 1985; Lewis and Mithchell, 1990). In this study, service quality is the effectiveness of the Takhmao OWSO in performing the service delivery to the local residents in a way that truly meets their expectations.

\subsection{SERVQUAL}

The service quality (SERVQUAL) model is a service quality framework which was developed in 1985 by Parasuraman et al. (1985) for clients to evaluate the quality of a service. It consists of 5 dimensions and 22 items for accessing client's perception. These 5 dimensions are tangibility, reliability, responsiveness, assurance, and empathy. 


\subsection{Single Window}

A "Single Window (SW)" is a facility that brings together of government services, or information about them, in order to reduce the amount of time and effort citizens must expend to find and obtain the services they need (Bent, Kernaghan and Marson, 1999). In Cambodia, the SW system is being adapted and implemented as a new mechanism for public service delivery and given the name of One Window Service Office (OWSO). It was initiated in 2008 with three major intentions to (a) respond to the needs of citizens and small businesses for certain administrative services to be delivered in an efficient, transparent, and accountable manner, (b) provide an avenue for mediating complaints and concerns of citizens and small businesses regarding the district administration, and (c) promote awareness and participation of citizens in decisions, policies, and programs of district governments (OWSO, 2012). Currently, this kind of integrated service office has been operated in 17 target municipalities and provinces nationwide.

\section{Research Methodology}

\subsection{Sample}

Two different groups of 170 participants (expectations and perception) at the Takhmao OWSO, Cambodia, filled in the survey questionnaires in this study. Convenience sampling was applied because the researcher selects the sample according to their accessibility and willingness. Each sample took approximately 20 minutes for questionnaire completion. Moreover, ten clients were randomly selected and 5 officers were purposive selected for interview to gain more in-depth understanding of their perception on service quality of Takhmao OWSO.

\subsection{Instruments}

This study employed both quantitative and qualitative approaches. Two sets of quantitative data collection instruments adapted from SERVQUAL developed by Parasuraman et al., 1985 were used: expectation questionnaire and perception questionnaire. These questionnaires contained 20 items which arranged into 5 dimensions and scored on a 5 point Likert scales from 1 (strongly disagree) to 5 (strongly agree). In addition, in order to find out deeper on the perceptions of clients and OWSO officers' challenges, in-depth interview was employed to collect the data.

\section{Findings and Discussions}

\subsection{Service Quality of the Takhmao OWSO}

In order to find out the level of service quality of the Takhmao OWSO, pair t-test was used to compare means of expectation and perception (see Table 1).

\begin{tabular}{|c|c|c|c|c|c|c|c|c|}
\hline & \multicolumn{5}{|c|}{ Paired Differences } & \multirow[b]{2}{*}{$t$} & \multirow{3}{*}{$d f$} & \multirow{3}{*}{$\begin{array}{c}\text { Sig. } \\
\text { (2-tailed) }\end{array}$} \\
\hline & \multirow[b]{2}{*}{$\bar{X}$} & \multirow[b]{2}{*}{$S D$} & \multirow[b]{2}{*}{ SD Error Mean } & \multicolumn{2}{|c|}{$\begin{array}{l}\text { 95\% Confidence Interval } \\
\text { of the Difference }\end{array}$} & & & \\
\hline & & & & Lower & Upper & & & \\
\hline $\begin{array}{l}\text { Overall Perceptions- } \\
\text { Overall Expectation }\end{array}$ & .47 & .68 & .05 & .36 & .57 & 8.95 & 169 & .000 \\
\hline
\end{tabular}

Table 1 Overall score of clients' expectations and perceptions

According to the Table 1, the overall service quality gap was found to be positive at statistically significant different .05 (Mean $=.47, S D=.68, p=.000, n=170)$. This result indicated that the perceptions exceed expectations. In other word, clients were delivered more than what they expected from the office. In this study, reliability dimension was highly appreciated and it obtained the largest gap score. Therefore, it can be deduced that the clients satisfied with the service provided by the Takhmao OWSO.

\subsection{The Challenges of the Takhmao OWSO}

From the emerging challenges of the Takhmao OWSO obtained from the in-depth interviews, three main issues which were the root cause of imperfection of the OWSO for delivering public services were integrated to be discussed. These were (1) lack of budget and financial autonomy, (2) lack of human resource, and (3) lack of horizontal cooperation. 


\begin{abstract}
4.2.1 Lack of Budget and Financial Autonomy

Financial issue played a potential role in operating the Takhmao OWSO. Since the costs for the OWSOs were under the control of the Ministry of Interior (MOI), the Takhmao OWSO did not have its own financial autonomy over their budget allocation or over the revenues collected. Revenues were transferred to the ministry where the ministry makes decision to share the budget to any specific OWSOs. The finding was consistent with the study conducted by CDRI (2011) that the budget allocation for the operation cost of the OWSOs was insufficient. That the results of lack of variety in services sought like equipment and office materials for the Takhmao OWSO were identified. This insufficient budget also demotivated of the officers due to the low basic salary and no incentive provided.
\end{abstract}

\subsubsection{Lack of Human Resource}

Occasionally, after the result of national examination of high school, the number of students who seek to have the certificates certified at the Takhmao OWSO significantly outnumbered the front officers. Besides, recently, in Cambodia, the restriction of traffic law was strongly enforced. That is, the vehicles and motorcycles were required to be registered for license plate number as a result of high demand of clients. Thus, front officersclients ratios emerged as the difficulties needing more attention. Likewise, back officers were delegated by line agencies such as Ministry of Commerce, Ministry of Public Works and Transportation, Ministry of Tourist, Ministry of Industry, Ministry of Culture and Fine Arts, and Ministry of Land Management and Urban Planning. However, only one officer from each ministry was assigned to work in the OWSO, who had to handle all the work and processes in the ministry. So it was the big challenge for them to responsible for numerous tasks. In addition, when there was one of the officers got sick and has to leave from work, the working process which responsible by that officer must get stuck.

\subsubsection{Lack of Horizontal Cooperation}

The success of the Takhmao OWSO depends upon the availability of the delegated power and authority provided by the line ministries. However, in this study, it was found that a wide range of bureaucratic administrative system was still practicing in this OWSO office. Many line departments did not completely provide the power to the office. This lack of cooperation and horizontal coordination between OWSO and lines department led to the disseminations of the administration. Therefore, such issue should be taken in account for the improvement to avoid ambiguity and frustration over unclear functions, with the government and the MOI. In this respect, the MOI must play a crucial role as facilitator to coordinate between all these related departments for the betterment of service delivery.

\section{Recommendation and Suggestions for Further Research}

Based on the above discussions, some key suggestions were proposed to OWSO management team at the Takhmao municipality as well as others OWSOs located in various districts and provinces in Cambodia to enable them function well and play a critical part in reform, particularly service delivery. These were as follows:

\subsection{Policy Suggestions}

The salary and incentive should be highly taken into consideration so that the officers may be motivated in their work. Thus, it can increase the quality of work life of the public officials. In other words, the salary should be increased, which can be compared to other organizations or private sectors. Moreover, incentive should be provided to any hard working and well performed officers in the purpose of more encouragement. This can lead to minimize the corruption in the work place.

\subsection{Operational Suggestions}

The weak resource allocation resulting in the lack of financial autonomy represents a major obstacle for the effectiveness of the local service delivery. In term of decentralization, central government delegate power and autonomy to the local government to take action on their own judgment (selfadministration). Thus, delegation of both the power and financial should be offered independently to the OWSO. Financial autonomy played important roles in the OWSO so it may be very necessary to reduce the large burden of OWSO's daily operational costs. In addition, the line ministries should delegate their relevant functions to OWSO both qualified human resources and sufficient. That is, pre and in-service training should be conducted to build up their capabilities and skills as well as to upgrade new knowledge. More importantly, in order to enhance the accessibility in the OWSO, the cooperation of the related departments should be strengthen firmly as a result of smooth and efficient working process. 


\subsection{Academic Suggestions}

Since there was a small sample size from one department of OWSO in Takhmao municipality in this study, the results would be more reliable and accurate if further studies were conducted on larger samples at various locations of OWSOs. Besides, the study was about the perception of the client satisfaction in the service of the OWSO as a whole. Thus, it was recommended that future research on the perception towards specific services should be worked in order that the level of the satisfaction of each service would be identified and improved. Last but not least, in terms of profitability and growth, such kind of measuring should be conducted every year in all OWSO in Cambodia in order to monitor service quality as well as to find out the level of client satisfaction and hence make necessary adjustments in case of any weaknesses and strengths.

\section{Conclusion}

Single Window (SW) or One Window Service Office (OWSO) is a new application of servicing in Cambodia and is used to eliminate in inefficiency and ineffectiveness of government procedures for local service delivery. Even though there were some deficits that have been considered major challenges of the Takhmao OWSO, the findings yielded that there was satisfaction of the clients that received the services provided through this integrated service office. This showed that the Royal Government of Cambodia has tried hard in reforming its administrative system for the betterment of public service delivery.

\section{References}

[1] Bent, S. Kernaghan, K.. Marson, D.B. Innovations and good practices in Single Window, Canadian Centre for Management Development, 1999: 1-3.

[2] Brysland, A. Curry, A. Service Improvements in Public Services Using SERVQUAL. Managing Service Quality, 2001, 11(6): 1-13.

[3] CDRI- Cambodia's leading independent development policy research institute. Annual development review, Phnom Penh, Cambodia, 2011: 193-209.

[4] Lewis, B.R. Mitchell, V.W. Defining and Measuring the Quality of Customer Service, Marketing Intelligence \& Planning, 1990, (8): 11-17.
[5] Parasuraman, A., Zeithml, V. A. and Berry, L. L. A Conceptual Model of Service Quality and Its Implications for Future Research, Journal of Marketing, 1985, (49): 42-51.

[6] One Window Service Office: http://owso.gov.kh/?page_id=1843: Retrieved on September 10, 2012 